\title{
Los inversores en energías renovables en España: litigiosidad y nuevo marco retributivo ${ }^{1}$
}

\author{
Alejandro D. Leiva López ${ }^{2}$
}

\section{RESUMEN}

En el presente trabajo se examinan los pronunciamientos de los tribunales y cortes de arbitraje internacionales en relación con las modificaciones a la baja del régimen de ayudas a las energías renovables que han tenido lugar en España durante los años 2013 y 2014. Esto permite entender la situación en la que se encuentran los inversores que vieron frustradas sus expectativas de rentabilidad, quienes solo han logrado obtener pronunciamientos estimatorios de sus pretensiones indemnizatorias de órganos de arbitraje internacionales. En este contexto, se ofrece un análisis del nuevo régimen retributivo aprobado a través del Real Decreto-ley 17/2019 y de sus posibles implicaciones sobre las decisiones futuras de los inversores en energías renovables en España.

Palabras clave: sector energético renovable, tarifa regulada, arbitraje de inversiones, Tratado sobre la Carta de la Energía, incentivos económicos.

1 Este trabajo se ha elaborado en el marco del proyecto de investigación "La regulación de la energía limpia: desafíos pendientes" (DER2017-83429-C2-1-R), financiado por el Mi-nisterio de Ciencia e Innovación (MCI), la Agencia Estatal de Investigación (AEI) y el Fondo Europeo de Desarrollo Regional (FEDER), Programa Estatal de I+D+i orientado a los "Retos de la Sociedad". de recepción: 4 de enero de 2020. Fecha de modificación: 2 de febrero de 2020. Fecha de acep-tación: 27 de abril de 2020. Para citar el artículo: LeIva LóPEZ, Alejandro D., "Los inversores en energías renovables en España: litigiosidad y nuevo marco retributivo", Revista digital de Derecho Administrativo, Universidad Externado de Colombia, n. ${ }^{\circ} 24,2020$, pp. 271-289. DOI: https://doi.org/10.18601/21452946.n24.11. 


\title{
Renewable Energy Investors in Spain: Legal Disputes and New Compensation Framework
}

\author{
ABSTRACT \\ This paper examines the decisions of national and international courts of arbi- \\ tration in relation to the downwards modifications in the scheme for renewable \\ energy incentives in Spain, during the years 2013 and 2014. This provides \\ an insight of the current situation of investors whose profit expectations fell \\ short after the scheme reform, and who were therefore awarded compensa- \\ tions by international courts of arbitration. On this basis, the research offers \\ an analysis of the new remuneration regime for energy production in Spain \\ (Royal Decree-Law 17/2019), and its potential implications on future inves- \\ tment decisions in this sector. \\ Keywords: Renewable Energy Sector, Feed-in Tariff, Investment Arbitra- \\ tion, the Energy Charter Treaty, Economic Incentives.

\section{INTRODUCCIÓN: EL FOMENTO DE LAS ENERGÍAS RENOVABLES EN ESPAÑA}

El fomento del uso de energía procedente de fuentes renovables en el sector eléctrico constituye un elemento clave que actúa sobre la oferta, junto a otras actuaciones sobre la demanda (tecnologías de eficiencia energética, ahorro energético... $)^{3}$, y que ha representado un carácter prioritario en las políticas energéticas y medioambientales dirigidas a cumplir los objetivos europeos de reducción de emisiones de gases de efecto invernadero. El fomento de la generación de electricidad basada en fuentes de energía renovables también ha constituido el objeto central de discusión en las declaraciones de intenciones extraídas del Acuerdo de París de 2015 (COP 21)4 Las energías renovables constituyen de esta forma una herramienta clave en la lucha contra el cambio climático; si bien hay que destacar que su regulación reviste gran complejidad

3 Para mayores desarrollos sobre estas medidas que actúan sobre la demanda, véase ISABEL GonZálezz Ríos, "Régimen jurídico de la eficiencia y el ahorro energéticos", Revista Jurídica de Navarra, n. ${ }^{\circ}$ 50, 2010, pp. 171-208; Isabel GonZÁlezz Ríos, "La mejora de la eficiencia energética en edificaciones del litoral (propuesta para una interpretación integrada de la legislación de costas y de la normativa sobre eficiencia energética)", Revista Española de Derecho Administrativo, n. ${ }^{\circ}$ 167, 2014, pp. 195-229; y Susana Galera Rodrigo, "Del ahorro de energía a la eficiencia energética: objetivos e instrumentos de las políticas europeas", Revista de Derecho Urbanístico y Medio Ambiente, n. ${ }^{\circ} 289$, 2014, pp. 85-120.

4 Este acuerdo se adoptó en la Cumbre del Clima de París, celebrada del 30 de noviembre al 11 de diciembre de 2015, en el seno de la 21 ${ }^{\text {a }}$ Conferencia de las Partes de la Convención Marco de las Naciones Unidas sobre el Cambio Climático de 2015 (Cop21/CMP11). 
y, por ello, lanza importantes retos a los poderes públicos ${ }^{5}$. Con la mayor utilización de este tipo de energías se persigue fomentar la seguridad del abastecimiento energético, la minoración de precios, la innovación tecnológica e industrial, y el empleo en zonas rurales no industrializadas, así como también lograr ventajas de carácter social, ambiental y sanitario ${ }^{6}$.

Las energías renovables contribuyen significativamente al cumplimiento del objetivo de producción con energía verde de un 20\% fijado para 2020 por la Estrategia energética de la Unión Europea ${ }^{7}$, así como también son una herramienta eficaz para alcanzar otros objetivos de política energética dirigidos a configurar un mercado interior de la electricidad seguro, competitivo y medioambientalmente sostenible. En este orden de cosas, la normativa europea ha venido considerando necesaria la adopción de medidas de apoyo a la generación de electricidad basada en fuentes de energía renovables, en la medida en que estas tecnologías limpias presentan costes totales mayores que aquellos en los que incurren las tecnologías de generación eléctrica convencionales ${ }^{8}, \mathrm{y}$ sin perjuicio de que en la actualidad existan algunas tecnologías renovables (especialmente la fotovoltaica) que han experimentado reducciones de costes muy significativas.

Los sistemas de apoyo a los generadores de electricidad procedente de fuentes de energía renovables han jugado un papel clave para incrementar la integración de esta electricidad renovable en el mercado. Se trata de unas ayudas destinadas a suplementar unos ingresos del mercado que para el inversor son insuficientes para cubrir costes, sin que ello suponga otorgar ventajas competitivas a ciertas empresas ni provoque falseamientos de la competencia, esto es, sin que estos sistemas de apoyo incurran en la prohibición de ayudas de Estado (ex artículo 107.1 TFUE). En este contexto, España ha experimentado desde 2010 un proceso continuo de reducción de ayudas, motivado por las propias circunstancias cambiantes del sector, por la mayor madurez de las tecnologías de generación renovable y, sobre todo, por el cuantioso déficit

5 Miren Sarasíbar Iriarte, "Los desafíos jurídicos de la estrategia de adaptación al cambio climático", en José Francisco Alenza García (dir.), La regulación de las energías renovables ante el cambio climático. Madrid: Aranzadi, 2014, pp. 217-218.

6 Rosa María Regueiro Ferreira, "La contribución de las energías renovables al bienestar Una lección todavía no aprendida", Revista Galega de Economía, vol. 20, Extra 2, 2011, p. 12.

$7 \quad$ El cual ha sido incrementado recientemente hasta un 32\% para el horizonte 2030. Esta estrategia es desarrollada por un conjunto de actuaciones provenientes de la Comisión Europea, del Consejo y del Parlamento Europeo, las cuales definen el compromiso de los "Cinco Veintes": 20\% de reducción de emisiones de gases de efecto invernadero, 20\% de reducción en el consumo de energía, promoviendo la eficiencia energética, y 20\% de la energía primaria consumida procedente de fuentes renovables.

8 Véase Manuel Campos SÁnChez Bordona, "Regulación como finalidad distinta al derecho a la competencia", en Javier Guillén Caramés (dir.), Derecho de la competencia y regulación en la actividad de las Administraciones públicas, Madrid: Thomson Civitas, 2011, p. 87. 
tarifario imputable al sistema eléctrico español. Ello ha ocasionado un elevado número de litigios nacionales e internacionales planteados por inversores afectados por estos cambios, y un intenso debate entre los distintos agentes e instituciones protagonistas del sector eléctrico.

Por consiguiente, el presente trabajo examina las disputas jurídicas que han ocasionado los cambios a la baja del régimen de ayudas previstos para este tipo de tecnologías de generación basados en fuentes de energía renovables, lo que tuvo lugar fundamentalmente durante los años 2013 y 2014. Se presta especial atención al nuevo régimen retributivo aprobado a través del Real Decreto-ley 17/2019, de 22 de noviembre, por el que se adoptan medidas urgentes para la adaptación de parámetros retributivos que afectan al sistema eléctrico, y por el que se da respuesta al proceso de cese de actividad de cen-

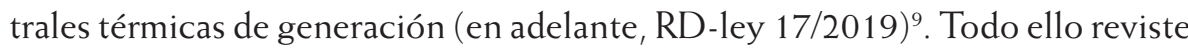
especial importancia a la luz de las prioridades establecidas en la Directiva (UE) 2018/2001 del Parlamento Europeo y del Consejo, del 11 de diciembre, relativa al fomento del uso de energía procedente de fuentes renovables ${ }^{10}$, pues esta define un objetivo vinculante de la UE de una cuota de, al menos, un $32 \%$ de energías renovables para 2030, pudiendo ser revisada al alza ante determinadas circunstancias (reducción de costes de generación o nuevos compromisos internacionales de la Unión Europea para la descarbonización).

\section{LA ELIMINACIÓN PROGRESIVA DE INCENTIVOS EN EL MARCO RETRIBUTIVO DE LAS ENERGÍAS RENOVABLES EN ESPAÑA}

Una primera configuración de los mecanismos de fomento de las energías renovables en España lo encontramos en la Ley de Ordenación del Sistema Eléctrico Nacional (LOSEN) ${ }^{11}$, y en su normativa de desarrollo sobre producción de energía eléctrica por instalaciones hidráulicas, de cogeneración y otras abastecidas por recursos o fuentes de energía renovable ${ }^{12}$. Se definió así el "régimen especial de producción de electricidad", el cual fomentaba el uso de estas tecnologías renovables obligando a las distribuidoras de la zona a adquirir la electricidad excedente de plantas renovables de potencia menor o igual a 100 MVA.

Destacadamente, es con la aprobación de la Ley del Sector Eléctrico ${ }^{13}$ cuando se empieza a impulsar un régimen retributivo para las tecnologías renovables basado en la concesión de ayudas a generadores, de una determinada potencia 
instalada, inscritos en registro relativo al mencionado régimen especial. En efecto, a partir de esta ley se han ido sucediendo numerosas convocatorias de ayudas ${ }^{14}$, entre las que cabe destacar la definida en el Real Decreto 436/2004, por el que se establece la metodología para la actualización y sistematización del régimen jurídico y económico de la actividad de producción de energía eléctrica en régimen especial ${ }^{15}$. Esta norma definió elevados márgenes de rentabilidad, especialmente para inversores en tecnología solar térmica y fotovoltaica. Se observaban tarifas de hasta un 575\% durante los primeros 25 años para la tecnología fotovoltaica de no más de $100 \mathrm{~kW}$ de potencia instala$\mathrm{da}^{16}$. También fue muy relevante la convocatoria establecida a través del Real Decreto 661/2007, por el que se regula la actividad de producción de energía eléctrica en régimen especial (en adelante, RD 661/2007) ${ }^{17}$. Esta convocatoria también definía un régimen de ayudas muy generoso para las tecnologías renovables, en especial termosolar y fotovoltaica. Se observaba, entre otras, una tarifa regulada de 44,0381 $\mathrm{c} € / \mathrm{kWh}$ para instalaciones fotovoltaicas, de potencia no superior a $100 \mathrm{~kW}$ de potencia instalada, durante los primeros 30 años de su puesta en marcha ${ }^{18}$. Prueba fehaciente de que se trataba de un régimen de incentivos significativamente generoso fue la inscripción masiva de productores que utilizaban tecnología solar, en el registro administrativo establecido para el régimen especial, hasta el punto de que la Secretaría General de Energía, a propuesta de la entonces Comisión Nacional de Energía, tuvo que reducir el plazo para llevar a cabo las inscripciones a doce meses.

Este modelo, claramente incentivador de las energías renovables, ocasionó un elevado déficit tarifario que ponía en riesgo la sostenibilidad del sistema eléctrico, pues debía ser soportado por los consumidores en la parte regulada de la factura eléctrica - hoy en día seguimos pagando por este déficit acumulado-. Por ello, el Ejecutivo tuvo que controlar el gasto público empleado en primas a las energías renovables, para lo que comenzó a llevar a cabo un progresivo recorte del régimen retributivo especial. Con estos recortes, llevados a cabo en un contexto de crisis financiera, se pretendía corregir un déficit tarifario que empezaba a ser inasumible por el consumidor ${ }^{19}$. Así pues, a partir de 2010, la normativa comienza a configurar a la baja el régimen de primas a

14 A mayor abundamiento, véase Alejandro D. Leiva LóPez, "Cambios de modelo retributivo de la generación renovable en España: la confianza del inversor frente al riesgo regulatorio", Revista Española de Derecho Administrativo, n. ${ }^{\circ}$ 188, 2017, pp. 133-137. 
renovables ${ }^{20}$. Una primera corrección tiene lugar con ocasión de la aprobación del Real Decreto 1565/2010, por el que se regulan y modifican determinados aspectos relativos a la actividad de producción de energía eléctrica en régimen especial (en adelante, RD 1565/2010) ) $^{1}$ y del Real Decreto-ley 14/2010, por el que se establecen medidas urgentes para la corrección del déficit tarifario del sector eléctrico (en adelante, RD-ley 14/2010)22. Tras estas modificaciones a la baja, se llega a la suspensión temporal del régimen especial a través del Real Decreto-ley $1 / 2012$, por el que se procede a la suspensión de los procedimientos de preasignación de retribución y a la supresión de los incentivos económicos para nuevas instalaciones de producción de energía eléctrica a partir de cogeneración, fuentes de energía renovable y residuos ${ }^{23}$. El régimen especial termina desapareciendo con el Real Decreto-ley 9/2013, por el que se adoptan medidas urgentes para garantizar la estabilidad financiera del sistema eléctrico (en adelante, RD-ley 9/2013) ${ }^{24}$.

Estos importantes cambios trajeron consigo la aprobación de un nuevo "régimen específico de producción de electricidad", a través de la Ley 24/2013 del Sector Eléctrico (en adelante, LSE) ${ }^{25}$, desarrollada por disposiciones reglamentarias que regulan la actividad de producción de energía eléctrica a partir de fuentes de energía renovables, cogeneración y residuos (RD 413/2014) ${ }^{26}$ y por la Orden Ministerial de 2014 que aprueba los parámetros retributivos de las instalaciones tipo aplicables a determinadas instalaciones de producción de energía eléctrica a partir de fuentes de energía renovables, cogeneración y residuos (en adelante, Orden IET/1045/2014) ${ }^{27}$. Se trata, en definitiva, de un cambio que persigue equiparar las distintas tecnologías en el mercado a medio plazo, de forma que con ello se disminuyan los sobrecostes del sistema ${ }^{28}$. En esta medida, esta radiografía sobre el régimen de ayudas al sector renovable en España muestra cómo los incentivos se han ido reduciendo progresivamente desde 2010, lo que ha afectado retroactivamente a numerosos inversores ${ }^{29}$.

20 Sobre esta materia, véase, in extenso, Roberto Galán Vioque, "El nuevo modelo español de fomento de las energías renovables en el contexto del Derecho de la Unión Europea y de la crisis económica", en Isabel González Ríos (dir.), Estudios jurídicos bispano-lusos de los servicios en red, Madrid: Dykinson, 2015, pp. 97-136.

21 Real Decreto 1565/2010, de 19 de noviembre. BOE n. ${ }^{\circ} 283$, de 23 de noviembre de 2010.

22 Real Decreto-ley 14/2010, de 23 de diciembre. BOE n. ${ }^{\circ} 312$, de 24 de diciembre de 2010.

23 Real Decreto-ley $1 / 2012$, de 27 de enero. BOE n. ${ }^{\circ} 24$, de 28 de enero de 2012.

24 Real Decreto-ley 9/2013, de 12 de julio. BOE n. ${ }^{\circ} 167$, de 13 de julio de 2013.

25 Ley 24/2013, de 26 de diciembre. BOE n. ${ }^{\circ} 310$, de 27 de diciembre de 2013.

26 Real Decreto 413/2014, de 6 de junio. BOE n. ${ }^{\circ} 140$, de 10 de junio de 2014.

27 Orden Ministerial 1045/2014, de 16 de junio. BOE $n{ }^{\circ}{ }^{\circ} 150$, de 20 de junio de 2014.

28 Aвel Estoa Pérez, óp. cit., pp. 2 -4.

29 Por su parte, en el epígrafe final de este trabajo examinamos el último cambio sobre el régimen retributivo de este tipo de tecnologías renovables, que ha tenido lugar con ocasión de la publicación del RD-ley 17/2019. 


\section{LOS RECORTES EN MATERIA DE AYUDAS COMO POSIBLE VIOLACIÓN DE LOS PRINCIPIOS DE SEGURIDAD JURÍDICA, CONFIANZA LEGÍTIMA E IRRETROACTIVIDAD DEL INVERSOR}

Estos cambios de modelo retributivo a la baja han sido considerados por el sector inversor renovable como contrarios a los principios de seguridad jurídica, confianza legítima e irretroactividad de disposiciones restrictivas de derechos ${ }^{30}$. Con carácter general, los inversores sostienen que las convocatorias de ayudas a las que concurrieron no les proporcionaron información suficiente sobre las consecuencias de sus decisiones económicas. No existían, por tanto, unas reglas ciertas de derecho que les otorgasen un mínimo de certidumbre y estabilidad regulatoria; lo que habría sido exigible desde la perspectiva del principio de seguridad jurídica. En este punto, cabe subrayar que este principio no podría impedir los cambios normativos que se justificasen por razones de objetividad y racionalidad ${ }^{31}$; siendo esta la posición mayoritaria mantenida por los tribunales españoles.

Con parecido argumento se ha puesto de manifiesto la posible vulneración del principio de confianza legítima, entendido como una ramificación del principio de seguridad jurídica. Los inversores sostienen que los cambios normativos, apoyados en el riesgo regulatorio, han frustrado sus expectativas económicas $^{32}$, las cuales surgieron como consecuencia de la confianza depositada en la norma. De nuevo, hay que destacar que el principio de confianza legítima no puede implicar la petrificación el marco legal definido, por lo que estarían justificados aquellos cambios que sean previsibles y derivados de exigencias de interés general.

Algunas voces se han pronunciado acerca de la posible naturaleza contractual que podrían presentar algunas convocatorias de ayudas a la producción renovable (especialmente las de 2004 y 2007): un contrato celebrado entre

30 La doctrina también se ha hecho eco de esta situación, véase, entre otros, José MaRía BAÑo LEÓN, "'Cave legislatorem'. Confianza en el legislador e interés general", en Juan Castro-Gil Amigo (dir.), Riesgo regulatorio en las energías renovables II, Madrid: Aranzadi, 2016 , pp. 81-102; LuCIANO José PAREJO AlFONSO, "Cambio regulatorio, sector eléctrico y estado de necesidad", en Juan Castro-Gil Amigo (dir.), Riesgo regulatorio en las energías renovables, Madrid: Aranzadi, 2015, pp. 29-72; y Ana Isabel Mendoza Losana, "Adiós al régimen especial de retribución de instalaciones de producción a partir de tecnologías renovables, cogeneración y residuos en la nueva Ley 24/2013, del Sector Eléctrico", Noticias Breves de Gómez-Acebo \& Pombo, 2014, pp. 1-5.

31 Jaime Rodríguez Arana, "El principio general del derecho a la confianza legítima", Ciencia Jurídica, vol. 2, n. ${ }^{\circ} 4,2013$, pp. 67-68.

32 Véase, en este sentido, Carlos Mingorance MarTín, "Energías renovables y riesgo regulatorio. Los principios de seguridad jurídica, irretroactividad y protección de la confianza legítima en el ámbito de la producción de energía eléctrica desde fuentes proambientales", Administración de Andalucía: Revista Andaluza de Administración Pública, n. ${ }^{\circ} 87,2013$, p. 163. 
Estado e inversor renovable ${ }^{33}$. Si admitimos esta tesis como válida, podría equipararse el "riesgo regulatorio" que asumen los inversores al "riesgo y ventura" inherente a todo contrato público ${ }^{34}$. Sin embargo, esta oferta del Estado (a través de convocatorias de ayudas) y su aceptación por parte de los inversores no puede considerarse un contrato administrativo (de conformidad con la Ley 9/2017, del 8 de noviembre, de Contratos del Sector Público ${ }^{35}$ ). Aunque esto no impide que se apliquen instrumentos similares a los mecanismos de restablecimiento del equilibrio económico previstos para los casos de modificación unilateral de los contratos públicos. Es exigible, por tanto, la configuración de un régimen transitorio que permita compensar económicamente a los inversores en energías renovables afectados.

Asimismo, los inversores aducen una posible vulneración del principio de prohibición de retroactividad de disposiciones restrictivas de derechos individuales; ${ }_{i}$ esto es, una aplicación retroactiva ilegítima de normas que modifican el régimen de ayudas a las energías renovables. De nuevo, hay que subrayar que este principio no implica en modo alguno el derecho a mantener una ayuda determinada de forma indefinida, sino que se tendrá derecho a obtener las primas durante el tiempo de aplicación de las mismas. Además, en este orden de cosas, hay que tener en cuenta la doctrina a favor de la posible retroactividad legítima de disposiciones desfavorables para el operador jurídico, lo que permitiría la aplicación de una nueva norma a situaciones jurídicas que no han agotado sus efectos y que nacieron con anterioridad a su entrada en vigor (la denominada retroactividad impropia $)^{36}$. En el debate renovable, este principio gana fuerza si se conecta con los de seguridad jurídica y confianza legítima.

33 Destacadamente, véase Tomás de la Cuadra-Salcedo Fernández del Castillo, "Riesgo regulatorio y contractualización de la regulación por operadores y poderes públicos", en Juan Castro-Gil Amigo (dir.), Riesgo regulatorio en las energías renovables II, Madrid: Aranzadi, 2015, pp. 78-79.

34 Íñigo del Guayo Castiella, "La Carta Internacional de la Energía en 2015 y las energías renovables. A propósito del Laudo de 21 de enero de 2016", Cuadernos de Energía, n. ${ }^{\circ} 47$, 2016, p. 55.

35 BOE n. ${ }^{\circ} 272$, de 09 de noviembre de 2017

36 A mayor abundamiento, véase FranCisco López MENUdo, "El principio de irretroactividad", en Los principios jurídicos del Derecho Administrativo, Juan Alfonso Santamaría Pastor (dir.), Madrid: La Ley Actualidad, 2010, pp. 141-176. 


\section{LOS PRONUNCIAMIENTOS NACIONALES E INTERNACIONALES SOBRE LOS RECORTES AL RÉGIMEN DE AYUDAS A LA ENERGÍA RENOVABLE}

\subsection{LA AUSENCIA DE VIOLACIÓN A LOS PRINCIPIOS \\ DEL INVERSOR EN TRIBUNALES ESPAÑOLES}

La posición mantenida por el Tribunal Supremo en relación con estos cambios de modelo retributivo a la baja, acontecidos desde 2010, es rotunda: rechazar que exista vulneración de los principios de irretroactividad, seguridad jurídica y confianza legítima. En numerosos pronunciamientos en este sentido han encontrado apoyo en la doctrina del "riesgo regulatorio", lo que justificaría suficientemente que los cambios normativos en el sector eléctrico -al igual que en otros sectores regulados deban ser previsibles para los operadores. En el caso que nos ocupa, estos operadores son inversores en energías renovables que deberían asumir los daños a su inversión que pudieran ocasionar los cambios de modelo retributivo ${ }^{37}$. En particular, a juicio del tribunal, se considera que los operadores no tienen derecho a la petrificación del sistema de ayudas -y por tanto deben estar sometidos al riesgo regulatorio- en la medida en que han acudido a un sistema ventajoso de primas que elimina por completo el riesgo empresarial, renunciando por tanto a ir directamente al mercado. Esto último se considera un argumento débil, pues en el momento de publicarse las convocatorias de ayudas, los productores renovables no "renuncian" al mercado, sino que más bien no existía para ellos un verdadero mercado, al no poder competir con las tecnologías convencionales.

Además, el alto tribunal resalta otros motivos que justificarían estas modificaciones de tarifas a la baja, como son: la madurez de algunas tecnologías renovables (especialmente, la fotovoltaica), la evolución de la "curva de aprendizaje" o la sobrecapacidad del sistema por exceso de potencia instalada de origen renovable. En este orden de cosas, destacan numerosas sentencias del Tribunal Supremo ${ }^{38}$, las cuales se han pronunciado sobre las impugnaciones de los cambios retributivos que llegaron de la mano del RD 1565/2010, del RD-ley 14/2010, del RD-ley 9/2013, del RD 413/2014 y de la Orden IET/1045/2014.

37 Inmaculada Revuelta Pérez, "Estándar del inversor prudente y confianza legítima", Revista de Administración Pública, n. ${ }^{\circ}$ 208, 2019, pp. 406-407. BOE n. ${ }^{\circ}$ 272, de 9 de noviembre de 2017.

38 SSTS de 13 de septiembre de 2012 (RCA 48/2011), 10 de diciembre de 2012 (RCA 138/2011), 29 de enero de 2013 (RCA 232/2012), 1 . $^{\circ}$ de julio de 2013 (RCA 305/2012), 3 de abril de 2014 (RCA 444/2014), 21 de enero de 2016 (RRCA 563/2012, 841/2012,627/2012, 507/2012 y $515 / 2012$ ), 1 . $^{\circ}$ de junio de 2016 (RRCA 493/2014, 787/2014, 657/2014, 652/2014, 564/2014, $631 / 2014,660 / 2014,661 / 2014,654 / 2014,653 / 2014,682 / 2014,630 / 2014,783 / 2014$, $641 / 2014,649 / 2014,650 / 2014,427 / 2014,752 / 2014,472 / 2014,647 / 2014$ y $651 / 2014)$ y 25 de enero de 2017 (RCA 871/2015), entre otras. 
Por su parte, el Tribunal Constitucional se pronunció a través de la Sentencia 270/2015, del 17 de diciembre (Recurso de inconstitucionalidad 5347-2013) ${ }^{39}$, declarando la constitucionalidad del sistema retributivo de las energías renovables definido en el RD-ley 9/2013. Ya no se trataba de enjuiciar modificaciones parciales de las generosas convocatorias de primas, sino un verdadero cambio de modelo retributivo (derogación del régimen especial de producción de electricidad). Los ponentes de la sentencia, coincidiendo con la línea defendida por el Tribunal Supremo, han entendido que la eliminación del régimen de incentivos contemplado en la norma no atenta contra los principios de irretroactividad, seguridad jurídica y confianza legítima. Por tanto, estaría justificada la medida en tanto se tenía conocimiento de la existencia de un elevado déficit tarifario, en un contexto de crisis financiera, que hacía tambalear la sostenibilidad económica del sistema eléctrico. Aunque cabe subrayar que, para la Unión Europea, esta crisis económica nunca ha supuesto un freno en sus políticas energéticas en materia de fomento de las energías renovables. Por tanto, el Tribunal Constitucional ha considerado que la medida contenida en el RD-ley 9/2013 era previsibles para un operador prudente y diligente, haciendo valer un riesgo regulatorio justificado por los motivos aducidos por el ejecutivo. Sin embargo, sobre esta sentencia se han vertido opiniones negativas ${ }^{40}$, a nuestro juicio acertadamente, que ponen de manifiesto las carencias de contenido y forma que la misma presenta. Incluso el propio voto particular pone de manifiesto tal circunstancia ${ }^{41}$. Así, los ponentes no han aportado nuevas reflexiones que enriquezcan el análisis de los principios constitucionales traídos a colación.

Por todo ello, en relación con los distintos pronunciamientos judiciales que han tenido lugar en los últimos años, entendemos que, con carácter general, es exigible a los tribunales españoles un mayor esfuerzo interpretativo que les permita probar suficientemente, como exige la jurisprudencia del Tribunal

39 BOE n. ${ }^{\circ} 19$, de 22 de enero de 2016. Recurso de inconstitucionalidad 5347-2013. Interpuesto por el Consejo de Gobierno de la Comunidad Autónoma de la Región de Murcia en relación con diversos preceptos del Real Decreto-ley 9/2013, del 12 de julio, por el que se adoptan medidas urgentes para garantizar la estabilidad financiera del sistema eléctrico. Límites a los decretos-leyes, principios de jerarquía normativa, seguridad jurídica y de irretroactividad de las normas restrictivas de derechos individuales: acreditación de la concurrencia del presupuesto habilitante; constitucionalidad de los preceptos legales que establecen un nuevo régimen retributivo para los titulares de las instalaciones de producción de energía eléctrica en régimen primado. Voto particular.

40 Véase, entre otros, José Francisco Alenza García, "Las energías renovables ante la fugacidad legislativa: la mitificación de los principios de (in)seguridad jurídica y de (des) confianza legítima: [A propósito de la STC 270/2015 sobre el nuevo sistema retributivo de las energías renovables]", Actualidad Jurídica Ambiental, n. ${ }^{\circ}$ 55, 2016, pp. 5-6.

41 Voto particular que formula el magistrado Juan Antonio Xiol Ríos, al que se adhieren los magistrados Adela Asua Batarrita y Fernando Valdés Dal-Re. 
de Justicia de la Unión Europea (TJUE) ${ }^{42}$, que no se dan los presupuestos del principio de confianza legítima y que el inversor medio no ha actuado como un operador prudente y diligente, en tanto debía haber previsto razonablemente los cambios normativos. Asimismo, los tribunales nacionales deben valorar, caso por caso, si existe una posible relación de naturaleza contractual Estado-inversor (especialmente en convocatorias que llegaron entre los años 2004 y 2008) y, en su caso, activar mecanismos de compensación económica, conforme a las reglas de la responsabilidad patrimonial de la Administración, cuando se constate un daño efectivo, real y evaluable. Este daño deberá ser cuantificado atendiendo a las especificidades de cada caso (convocatoria de ayudas a la que concurren los inversores, norma impugnada y, sobre todo, tipo de tecnología). De lo contrario, los inversores renovables se encuentran en la injusta situación de estar sometidos a un régimen retributivo fuertemente regulado, pero sin tener derecho al restablecimiento del equilibrio económico en caso de producirse daños.

\subsection{LAS CONDENAS EN ARBITRAJES INTERNACIONALES}

\subsubsection{Marco legal y legitimidad}

El artículo 26 del Tratado sobre la Carta de la Energía (en adelante, TCE) apela a la resolución amigable de posibles controversias que pudieran suscitarse entre una parte contratante y un inversor de otra parte contratante (siendo parte contratante, entre otros muchos países, el Estado español) respecto al incumplimiento de aquella de una obligación determinada en relación con las inversiones que se realicen en su territorio. En su defecto, el TCE otorga al inversor extranjero la posibilidad de someter la controversia, además de a los tribunales nacionales del país donde realiza la inversión, a un arbitraje internacional ante: a) el Centro Internacional para el Arreglo de Diferencias relativas a Inversiones $(\mathrm{CIADI})_{\text {; }}$ b) un único árbitro internacional o tribunal de arbitraje ad boc constituido según lo dispuesto en el Reglamento de Arbitraje de la Comisión de las Naciones Unidas para el Derecho Mercantil Internacional (CNUDMI); y c) el Instituto de Arbitraje de la Cámara de Comercio de Estocolmo (IACCE). En este punto, cabe subrayar que existen inversores españoles con filiales o sociedades vinculadas al extranjero que podrían beneficiarse de estos arbitrajes internacionales, lo que estaría generando un agravio comparativo respecto de otros inversores españoles, generalmente de menor tamaño, que no se encontrarían en tal situación.

42 A mayor abundamiento sobre la falta de adecuación de las sentencias de tribunales españoles a la jurisprudencia del TJUE sobre confianza legítima, véase INMACULADA REvUELTA PÉREZ, óp. cit., pp. 425-430. 
Sobre la legitimidad de los arbitrajes, cabe significar que el Estado español, para tratar de sortear los fallos condenatorios que van sucediéndose $e^{43}$, busca impedir que se atribuya esta función de resolución de controversias en materia de inversiones renovables a los órganos arbitrales internacionales señalados, aduciendo que el artículo 26 TCE presenta una "cláusula de desconexión" implícita que estaría excluyendo la posibilidad de arbitraje cuando se suscite entre un inversor de un Estado contratante de la UE y un Estado contratante de la $\mathrm{UE}_{i}$ es decir, una excepción intra-UE. Para sostener esta tesis, España parte de la premisa de que cuando el inversor de un Estado de la UE invierte en otro Estado de la UE, no puede entenderse que ese inversor provenga de "otra parte contratante" -como exige el artículo 26 TCE-, sino que el Estado donde se efectúa la inversión y el Estado del que procede el inversor son una misma parte contratante: la Unión Europea. A ello se añade que, en la medida en que se establece que los árbitros decidirán en base a las disposiciones del propio TCE y a las normas del derecho internacional aplicables (artículo 26.6 TCE), debe entenderse que dentro de las "normas del derecho internacional aplicables" se localiza la normativa de la UE $\mathrm{U}_{i}$ la cual atribuye, en el artículo 344 TFUE, la competencia exclusiva para decidir sobre el significado y el sentido del derecho europeo (en este caso, en materia de confianza legítima) al Tribunal de Justicia de la Unión Europea (TJUE), sin que pueda darse la intervención de otro órgano. Sin embargo, los árbitros internacionales han rechazado esta tesis, aduciendo que, según los criterios que deben guiar la interpretación del TCE -los cuales aparecen definidos en la Convención de Viena sobre el Derecho de los Tratados-, debe presumirse la buena fe del redactor del TCE y, por tanto, su voluntad de no incluir ninguna excepción intra-UE. Los órganos arbitrales entienden de forma acertada que para existir tal excepción es necesario que las partes contratantes incluyan esta pretensión en el texto del TCE de forma expresa e inequívoca, de conformidad con el principio del derecho internacional "pacta sunt servanda". Por ende, no es posible entender que el TCE quiera incluir una excepción intra-UE, máxime si tenemos en cuenta que este mecanismo de arbitrajes internacionales aparece contenido en un tratado multilateral suscrito por la propia Unión Europea.

\subsubsection{Contenido de los laudos}

Hasta la fecha se han sustanciado doce laudos arbitrales que han estimado las pretensiones de los fondos de inversión, condenando así al Estado español

43 El más reciente, a la fecha en que se escriben estas líneas, es el laudo arbitral del CIADI, de diciembre de 2019, que obliga a España a pagar cerca de 60 millones de euros a RREEF (Fondo de Infraestructuras de Deutsche Bank). Véase https://elperiodicodelaenergia. com/espana-vuelve-a-perder-otro-arbitraje-por-el-hachazo-renovable-tendra-que-pagar60-millones-a-un-fondo-del-deutsche-bank/. 
a resarcir a los inversores a través de elevadas indemnizaciones. Las normas impugnadas pertenecen al periodo de recortes 2013-2014, fundamentalmente el RD-ley 9/2013, el RD 413/2014 y la Orden IET/1045/2014. Se alega que estos recortes habrían afectado negativamente a la rentabilidad de las inversiones (en tecnología fotovoltaica y termosolar) efectuadas en el marco de convocatorias de ayudas (principalmente la definida en el RD 661/2007). Cabe destacar, entre otros, los casos Eiser ${ }^{44}$, Novenergia II ${ }^{45}$, Masdar ${ }^{46}$ o Antin ${ }^{47}$. No obstante, con carácter general, las pretensiones de resarcimiento de daños como consecuencia de las revisiones retributivas que tuvieron lugar entre el año 2009 y 2012 no han prosperado (véase el caso Charanne ${ }^{48}$ ), pues los órganos arbitrales no observaron que las medidas correctoras -crear límites máximos de horas anuales con derecho a retribución y límites de vida útil de las instalaciones- provocaran un daño real a la inversión.

En este orden de cosas, los árbitros internacionales se han pronunciado acerca de la posible vulneración de los artículos 10 y 13 del TCE, en relación con el trato justo y equitativo, y con la expropiación de inversiones, respectivamente. Para valorar la posible vulneración debe tenerse en cuenta el marco jurídico vigente u otros compromisos estatales firmes en la fecha en que tuvo lugar la inversión, pues deben evaluarse las expectativas que se generaron para el inversor en tal fecha. El artículo 10 TCE dispone que

las Partes Contratantes fomentarán y crearán condiciones estables, equitativas, favorables y transparentes para que los inversores de otras Partes Contratantes realicen inversiones en su territorio. Entre dichas condiciones se contará el compromiso de conceder en todo momento a las inversiones de los inversores de otras Partes Contratantes un trato justo y equitativo.

Para valorar si se atenta contra este trato justo y equitativo debe atenderse al impacto real de las medidas revisoras sobre el valor de la inversión, para, en su caso, resarcir el daño causado al inversor. En este sentido, el CIADI (caso Eiser) llegó a entender que era necesario que las revisiones normativas destruyesen, aniquilasen o neutralizasen el valor de inversión. Sin embargo, el IACCE viene utilizando criterios más flexibles que, en base a diversos factores (considerar que las medidas provocan un efecto radical e inesperado), buscaba equilibrar

44 Eiser Infrastructure Limited and Energía Solar Luxembourg S.à r.l. vs. Kingdom of Spain ICSID Case No. ARB/13/36. May 2017.

45 Novenergia II - Energy \& Environment (SCA) (Grand Duchy of Luxembourg), SICAR vs. The Kingdom of Spain. SCC Arbitration (2015/063). Feb 2018.

46 Masdar Solar \& Wind Cooperatief U.A. vs. Kingdom of Spain. ICSID Case No. ARB/14/1 May 2018.

47 Antin Infrastructure Services Luxembourg S.à.r.l. and Antin Energia Termosolar B.V. vs. Kingdom of Spain. ICSID Case No. ARB/13/31. Jun. 2018. 
los intereses reguladores y las expectativas legítimas de los inversores, de forma que el daño al valor de la inversión ya no constituiría el único factor a tener en cuenta a la hora de apreciar una posible vulneración del artículo 10 TCE (véase el caso Novenergia II). Ello ha ocasionado que las pretensiones de los inversores hayan sido mayoritariamente aceptadas, sobre la base de una vulneración del trato justo y equitativo.

A su turno, el artículo 13 TCE establece que "Las inversiones de los inversores de una Parte contratante en el territorio de otra Parte contratante no serán objeto de nacionalización, expropiación o medida o medidas de efecto equivalente a la nacionalización o a la expropiación", salvo que la expropiación se haga por motivo de interés general, de forma no discriminatoria, con arreglo al debido procedimiento legal o mediante el pago de indemnizaciones adecuadas, efectivas y rápidas. Sobre este aspecto, cabe significar que los órganos arbitrales no vienen considerando, en ningún caso, que tal expropiación tenga lugar, pues para ello es necesario que los cambios normativos produzcan un efecto no solo radical e inesperado, sino también devastador y destructivo. Hasta el punto de entender que para que tenga lugar la expropiación -algo que no han considerado en ningún caso-, es necesario que el inversor sufra una pérdida de la propiedad industrial (centrales de generación e instalaciones asociadas) y de las acciones que posee, no bastando con que la rentabilidad de las acciones se vea afectada, sino que es preciso que la pérdida de valor sea de tal magnitud que equivalga a la privación total o parcial de la inversión ${ }^{49}$. Por tanto, en relación con el artículo 13 TCE, coinciden todos los árbitros en que debe utilizarse un criterio más rígido que el previsto para el artículo 10 TCE. En cualquier caso, basta con que los órganos arbitrales admitan el incumplimiento del debido trato justo y equitativo para fallar a favor de los inversores afectados $y$, en consecuencia, reconocer su derecho a ser indemnizados.

\section{EL NUEVO ESCENARIO RETRIBUTIVO EN ESPAÑA}

Tras analizar la litigiosidad que han ocasionado los recortes de ayudas a las energías renovables (que fundamentalmente tuvieron lugar en el periodo 2013-2014), corresponde ahora abordar el nuevo régimen retributivo que se ha configurado a través del RD-ley 17/2019, el cual establece modificaciones en la LSE; específicamente, en relación con la retribución de instalaciones renovables, introduce una disposición final tercera bis. La norma tiene por objeto determinar el valor de la rentabilidad razonable que va a ser de aplicación

49 EnRIQUE FERnÁNDEZ MASIÁ, "España ante el arbitraje internacional por los recortes a las energías renovables: una representación en tres actos, por ahora", Cuadernos de Derecho Trasnacional, vol. 9, n. ${ }^{\circ}$ 2, 2017, p. 670. 
para aquellos generadores renovables pertenecientes al régimen retributivo específico.

La regla general prevista en el RD-ley 17/2019 establece que la rentabilidad razonable de aplicación para el cálculo de la retribución durante el siguiente periodo regulatorio (2020-2025) será del 7,09\%, lo que supone suscribir la tasa ya propuesta por la Comisión Nacional de los Mercados y la Competencia (en adelante, CNMC) en el informe ${ }^{50}$ que el Gobierno le requirió, de conformidad con lo dispuesto en el párrafo segundo del artículo 19.2 RD 413/2014. Asimismo, se trata de la misma tasa de retribución financiera que aparecía en el Anteproyecto de Ley por el que se establecía la rentabilidad razonable de estas instalaciones $^{51}$, el cual fue aprobado por el Consejo de Ministros en fecha 28 de diciembre de 2018, pero finalmente no fue tramitado. Como excepción, se prevé la posibilidad de prorrogar el actual valor de la rentabilidad razonable establecido en el RD 413/2014 (7,389\%) durante los dos siguientes periodos regulatorios (2020-2031) para instalaciones con retribución primada reconocida a la entrada en vigor del RD-ley 9/2013, con los siguientes matices: 1) estas instalaciones pueden renunciar a la prórroga excepcional si lo manifiestan de forma fehaciente, y antes del $1 .^{\circ}$ de abril de 2020, ante la Dirección General de Política Energética y Minas (DGPEyM); 2) esta prórroga no será de aplicación para aquellas instalaciones cuya rentabilidad sea o haya sido objeto de un procedimiento arbitral o judicial ${ }^{52}$ fundado en las modificaciones del régimen retributivo especial que tuvieron lugar en 2013 y 2014, aunque esta exclusión podrá evitarse si antes del 30 de septiembre de 2020 se acredita ante la DGPEyM: a) la terminación anticipada del procedimiento arbitral o judicial y la renuncia fehaciente a su continuación o reinicio. Lo que excluiría a aquellos que iniciaron en el pasado procedimientos judiciales sin éxito a los que, por tanto, ya no puede renunciarse por estar finalizados; o b) la renuncia

50 Acuerdo por el que se aprueba la propuesta de metodología de cálculo de la tasa de retribución financiera de la actividad de producción de energía eléctrica a partir de fuentes de energía renovables, cogeneración y residuos para el segundo periodo regulatorio 20202025. Expediente: INF/DE/113/18, Sala de Supervisión Regulatoria, Madrid, 30 de octubre de 2018.

51 Anteproyecto de ley por el que se fija para el periodo regulatorio 2020-2025 la tasa de retribución financiera de las actividades de transporte y distribución de energía eléctrica y de producción en los sistemas eléctricos de los territorios no peninsulares con régimen retributivo adicional y por el que se establece la rentabilidad razonable de las actividades de producción de energía eléctrica a partir de fuentes de energía renovables, cogeneración de alta eficiencia y residuos con régimen retributivo específico, 28.12.2018.

52 A los efectos de esta excepción, se entienden como procedimiento arbitral o judicial: a) los procedimientos planteados por el titular, directo o indirecto, de la instalación renovable en cuestión; b) los procedimientos planteados por aquellos que pretendan hacer valer sus derechos como consecuencia de ser titulares de una inversión en relación con esas instalaciones renovables; y c) los procedimientos que planteen terceros en virtud de cesión, subrogación, sucesión procesal o cualquier otro título jurídico de efecto equivalente. 
a percibir la compensación económica que se hubiera reconocido, en su caso, en el marco de un arbitraje o procedimiento judicial ${ }_{i}$ y 3) la DGPEyM podrá revocar este régimen retributivo excepcional si constata que las instalaciones referidas han percibido una indemnización o compensación reconocida en un procedimiento arbitral o judicial. Esta revocación implicará la detracción de la retribución que corresponda percibir a la instalación de las cantidades que hubiera percibido indebidamente.

En relación con el plazo (antes de 2020) para aprobar la orden ministerial sobre la revisión de parámetros retributivos de este tipo de instalaciones (ex artículos 20.1 RD 413/2014 y 14.4 LSE), conviene anotar que el RD-ley 17/2019 extiende el mismo hasta el 29 de febrero de 2020. Aunque ello no impide que los parámetros retributivos sean aplicables desde el inicio del período regulatorio: $1 .^{\circ}$ de enero de 2020 . Por tanto, hasta llegada la orden ministerial, se procederá a liquidar las cantidades devengadas de acuerdo con la retribución que vienen percibiendo, sin perjuicio de las liquidaciones que correspondería compensar una vez aprobada la orden (Disposición adicional única del RD-ley 17/2019).

Con este real decreto-ley se busca otorgar certidumbre jurídica al marco retributivo de las instalaciones basadas en fuentes de energías renovables, y en particular a aquellas que ya tenían reconocida la retribución primada a la entrada en vigor del RD-ley 9/2013. La tasa de retribución financiera definida para las tecnologías renovables se basa en el weighted average cost of capital (WACC), siendo este un criterio técnico basado en una fórmula matemática que permite calcular el coste promedio ponderado del capital, reflejando el coste de la deuda y la rentabilidad exigida por los accionistas que aportan fondos propios a la empresa. Entendemos este criterio como acertado, pues facilita la predictibilidad de las tasas, reduce la incertidumbre y, en consecuencia, podría fomentar la inversión. Cabe destacar que el uso del método WACC también ha sido empleado recientemente por la CNMC para configurar la tasa de retribución financiera de las actividades de transporte y distribución de electricidad, y de regasificación, transporte y distribución de gas natural ${ }^{53}$. En definitiva, es un método de cálculo adecuado que además está ampliamente extendido en Europa.

\section{CONCLUSIONES}

El nuevo régimen retributivo definido en el RD-ley 17/2019 es, con carácter general, continuista del modelo anterior fijado desde 2013 (RD-ley 9/2013), aunque podría suponer un gran logro en relación con los laudos arbitrales

53 Circular 2/2019, de 12 de noviembre, de la Comisión Nacional de los Mercados y la Competencia, por la que se establece la metodología de cálculo de la tasa de retribución financiera de las actividades de transporte y distribución de energía eléctrica, y regasificación, transporte y distribución de gas natural. BOE n. ${ }^{\circ} 279$, de 20 de noviembre de 2019 . 
internacionales, pues las posibles renuncias podrían dar por cerrada la litigiosidad generada fundamentalmente por el régimen de primas que se aprobó con el RD 661/2007. Esta retirada de las demandas podría evitar una subida muy significativa del precio medio de las facturas eléctricas, pues hay 10.000 millones de euros de indemnizaciones en juego en distintos tribunales y cortes de arbitrajes internacionales ${ }^{54}$, que deberán ser soportados en la factura (vía costes regulados). En este sentido, ajustar los costes que soportan los consumidores en la factura eléctrica constituye una prioridad inaplazable, pues España presenta una de las facturas más elevadas de Europa. Por ello, esta medida es bien recibida en aras de intentar ahorrar al consumidor un elevado coste en concepto de indemnizaciones. Cosa distinta es que la norma produzca el efecto esperado, pues parece difícil concebir que unos fondos de inversión beneficiarios de elevadas indemnizaciones, o a la espera de obtener un laudo favorable, renuncien por evitar una bajada del 7,389\% al 7,09\% y por obtener una seguridad jurídica retributiva durante doce años, lo que es cuando menos dudoso a la vista del precedente en materia de régimen de ayudas para este tipo de instalaciones.

\section{BIBLIOGRAFÍA}

Alenza García, José Francisco. "Las energías renovables ante la fugacidad legislativa: la mitificación de los principios de (in)seguridad jurídica y de (des)confianza legítima: [A propósito de la STC 270/2015 sobre el nuevo sistema retributivo de las energías renovables]". Actualidad Jurídica Ambiental, n. ${ }^{\circ}$ 55, 2016, pp. 1-19.

Baño LeÓn, José María. "'Cave legislatorem'. Confianza en el legislador e interés general". En Juan Castro-Gil Amigo (dir.), Riesgo regulatorio en las energías renovables II (pp. 81-102). Madrid: Aranzadi, 2016.

Campos Sánchez Bordona, Manuel. "Regulación como finalidad distinta al derecho a la competencia". En Javier Guillén Caramés (dir.), Derecho de la competencia y regulación en la actividad de las Administraciones públicas (pp. 87-103). Madrid: Thomson Civitas, 2011.

De la Cuadra-Salcedo Fernández del Castillo, Tomás. "Riesgo regulatorio y contractualización de la regulación por operadores y poderes públicos". En Juan Castro-Gil Amigo (dir.), Riesgo regulatorio en las energías renovables II (pp. 29-80). Madrid: Aranzadi, 2015.

54 Véase https://elperiodicodelaenergia.com/espana-vuelve-a-perder-otro-arbitraje-por-elhachazo-renovable-tendra-que-pagar-60-millones-a-un-fondo-del-deutsche-bank/. 
Del Guayo Castiella, Íñigo. "La Carta Internacional de la Energía en 2015 y las energías renovables. A propósito del Laudo de 21 de enero de 2016". Cuadernos de Energía, n. ${ }^{\circ} 47,2016$, pp. 50-56.

Estoa Pérez, Abel. "Desincentivos para la obtención de incentivos a la generación renovable". Revista General de Derecho Administrativo, n. ${ }^{\circ} 38,2015$, pp. 1-34.

FERnÁNDEZ Masiá, ENRIQUE. "España ante el arbitraje internacional por los recortes a las energías renovables: una representación en tres actos, por ahora". Cuadernos de Derecho Trasnacional, vol. 9, n. ${ }^{\circ}$ 2, 2017, pp. 666-676.

Galán Vioque, Roberto. "El nuevo modelo español de fomento de las energías renovables en el contexto del Derecho de la Unión Europea y de la crisis económica". En Isabel González Ríos (dir.), Estudios jurídicos bispano-lusos de los servicios en red (pp. 97-136). Madrid: Dykinson, 2015.

Galera Rodrigo, Susana. "Del ahorro de energía a la eficiencia energética: objetivos e instrumentos de las políticas europeas". Revista de Derecho Urbanístico y Medio Ambiente, n. ${ }^{\circ}$ 289, 2014, pp. 85-120.

GonZÁLEZ Ríos, ISABEL. "La mejora de la eficiencia energética en edificaciones del litoral (propuesta para una interpretación integrada de la legislación de costas y de la normativa sobre eficiencia energética)". Revista Española de Derecho Administrativo, n. ${ }^{\circ} 167,2014$, pp. 195-229

GonZÁlez Ríos, Isabel. "Régimen jurídico de la eficiencia y el ahorro energéticos". Revista Jurídica de Navarra, n. ${ }^{\circ}$ 50, 2010, pp. 171-208.

Leiva LóPez, Alejandro D. "Cambios de modelo retributivo de la generación renovable en España: la confianza del inversor frente al riesgo regulatorio". Revista Española de Derecho Administrativo, n. ${ }^{\circ} 188,2017$, pp. 125-160.

López Menudo, Francisco. "El principio de irretroactividad". En Juan Alfonso Santamaría Pastor (dir.), Los principios jurídicos del Derecho Administrativo (pp. 141-176). Madrid: La Ley Actualidad, 2010.

Mendoza Losana, Ana Isabel. "Adiós al régimen especial de retribución de instalaciones de producción a partir de tecnologías renovables, cogeneración y residuos en la nueva Ley 24/2013, del Sector Eléctrico", Noticias Breves de Gómez-Acebo \& Pombo, 2014, pp. 1-5.

Mingorance Martín, Carlos. "Energías renovables y riesgo regulatorio. Los principios de seguridad jurídica, irretroactividad y protección de la confianza legítima en el ámbito de la producción de energía eléctrica desde fuentes proambientales". Administración de Andalucía: Revista Andaluza de Administración Pública, n. ${ }^{\circ}$ 87, 2013, pp. 137-185. 
Parejo Alfonso, Luciano José. "Cambio regulatorio, sector eléctrico y estado de necesidad". En Juan Castro-Gil Amigo (dir.), Riesgo regulatorio en las energías renovables (pp. 29-72). Madrid: Aranzadi, 2015.

Regueiro Ferreira, Rosa María. "La contribución de las energías renovables al bienestar. Una lección todavía no aprendida". Revista Galega de Economía, vol. 20, Extra 2, 2011, pp. 197-212.

Revuelta Pérez, InMaculada. "Estándar del inversor prudente y confianza legítima". Revista de Administración Pública, n. ${ }^{\circ}$ 208, 2019, pp. 403-430.

Rodríguez Arana, Jaime. "El principio general del derecho a la confianza legítima". Ciencia Jurídica, vol. 2, n. ${ }^{\circ}$ 4, 2013, pp. 59-70.

Sarasíbar Iriarte, Miren. "Los desafíos jurídicos de la estrategia de adaptación al cambio climático". En José Francisco Alenza García (dir.), La regulación de las energías renovables ante el cambio climático (pp. 217-248). Madrid: Aranzadi, 2014.

\section{Tribunal Constitucional Español}

STC 270/2015, de 17 de diciembre (Recurso de inconstitucionalidad 5347-2013).

\section{Tribunal Supremo Español}

STS de 13 de septiembre de 2012 (RCA 48/2011).

STS de 10 de diciembre de 2012 (RCA 138/2011).

STS de 29 de enero de 2013 (RCA 232/2012).

STS de $1 .{ }^{\circ}$ de julio de 2013 (RCA 305/2012).

STS de 3 de abril de 2014 (RCA 444/2014).

STS de 21 de enero de 2016 (RRCA 563/2012, 841/2012, 627/2012, 507/2012 y 515/2012).

STS de $1 .{ }^{\circ}$ de junio de 2016 (RRCA 493/2014, 787/2014, 657/2014, 652/2014, 564/2014, $631 / 2014,660 / 2014,661 / 2014,654 / 2014,653 / 2014,682 / 2014,630 / 2014,783 / 2014$, $641 / 2014,649 / 2014,650 / 2014,427 / 2014,752 / 2014,472 / 2014,647 / 2014$ y 651/2014).

STS de 25 de enero de 2017 (RCA 871/2015). 